\title{
Assessment of risk-forming factors of construction production in conditions of uncertainty
}

\author{
Andrey Schreiber, Ivan Abramov*, and Zaid Al-Zaidi \\ Moscow State University of Civil Engineering, 129377, Moscow, Russia
}

\begin{abstract}
Many changes have occurred in the construction industry over the past few years as a result of the development of technologies and specifications of the materials used and modern technologies, which led to an increase in the accuracy and speed of implementation of various stages of the project life cycle, and it became important to anticipate external and internal risks of the project and plan a response to these risks, since they have the effect of an unaccounted price increase and an excess of the contract period. From this perspective, risk assessment was a necessary tool to determine the risks to which the project was exposed in order to find the best way to deal with them. The aim of the study is to identify the most significant types of risk factors faced by the construction industry, which lead to exceeding the specified time for implementation and to large losses, which helps stakeholders in this area to predict potential obstacles and be able to quickly make appropriate decisions. To achieve this goal, a questionnaire survey was conducted to collect information from specialists in the construction industry, as well as references in this field to express an opinion on the intensity of the impact of each studied risk factor. Thereafter, Monte Carlo simulations were used to assess the risk factors studied. The study found that Monte Carlo simulations, which depend on repeated scenarios hundreds or thousands of times, can provide an accurate estimate of the risks faced by investment and construction projects in conditions of uncertainty.
\end{abstract}

\section{Introduction}

Investment and construction projects have a special character, its most important features are the duration of the periods and the multiplicity of stages, from the stage of receiving the project, the implementation process to the stage of final delivery and operation, which can lead to a change in circumstances leading to an increase in the state of uncertainty and an increase in the likelihood of risks, which reflected negatively on the quality, cost and duration of the construction project.

\footnotetext{
*Corresponding author: ivan2193@yandex.ru
} 
It can be said that the construction process includes a set of overlapping processes (planning, implementation, technical, economic) and others, which are often difficult to separate, determine the causes and relationships, as a result of this overlap and interdependencies between the various parties involved in the project, a risk factor acts as an influencing factor in the decision-making process affecting the course of construction, it is obvious that the risk is associated with the consequences of uncertainty [1-2].

Uncertainty in modern science is largely due to the dynamism of the external environment, which manifests itself in a change in the conditions of the legal, political, economic, social and other spheres within which the organization carries out its activities [3-4].

Construction enterprises that create high-quality and accordingly demanded construction products, it is necessary in advance, at the planning stage of construction industry, to protect their activities from the influence of relevant risks and uncertainties in order to maintain a given sustainable functioning [5]. Therefore, it is necessary to note the importance of participation and cooperation between the parties involved in the construction process in order to understand the risks and potential problems, determine how to solve them, this is achieved by assessing and analyzing the factors causing these risks in conditions of uncertainty.

The questionnaire used a Likert scale from 1 to 5 as in Table 1, this scale is the most widely used in statistical research. The data obtained was analyzed using quantitative statistical methods to rank the listed factors according to their importance, which helped to avoid or reduce their impact.

Table 1. The matrix of risk factors

\begin{tabular}{ccccc}
\hline 1 & 2 & 3 & 4 & 5 \\
\hline Ineffective & Minor & Medium impact & high impact & Catastrophic \\
\hline
\end{tabular}

Then, the results obtained using the statistical method are compared using the Monte Carlo simulation method, since this is one of the methods for the quantitative analysis of risk factors under conditions of uncertainty. The Monte Carlo technique uses special software, since the principle of this method is to implement certain scenarios thousands of times in order to calculate the probability of achieving a certain goal and assign certain values to these probabilities.

The investor's application of the Monte Carlo method provides him with a sufficient set of data that characterize the risks of the project. On this basis, he makes an objective and balanced decision on the provision of funds necessary for the implementation of the project [6].

The advantages of the Monte Carlo method are as follows [7]:

- Allows to assess the risk of the project;

- Allows to make a forecast regarding the occurrence of possible unfavorable situations, the occurrence of losses;

- Risks are expressed in numerical terms, which makes it easier to assess their impact on the results of construction activities;

- Allows you to form a realistic budget and determine the most optimal order of work;

- Facilitates the risk management process;

- Allows to make management decisions based on objective data;

- Allows to determine the likelihood of achieving the goals of the project;

There are different approaches to the classification of risk factors depending on a specific goal [8-9]. Risk factors for investment and construction projects can be divided 
into external and internal factors, while others classify them into more detailed sections, such as organizational, economic, technical, market, social, safety factors and others.

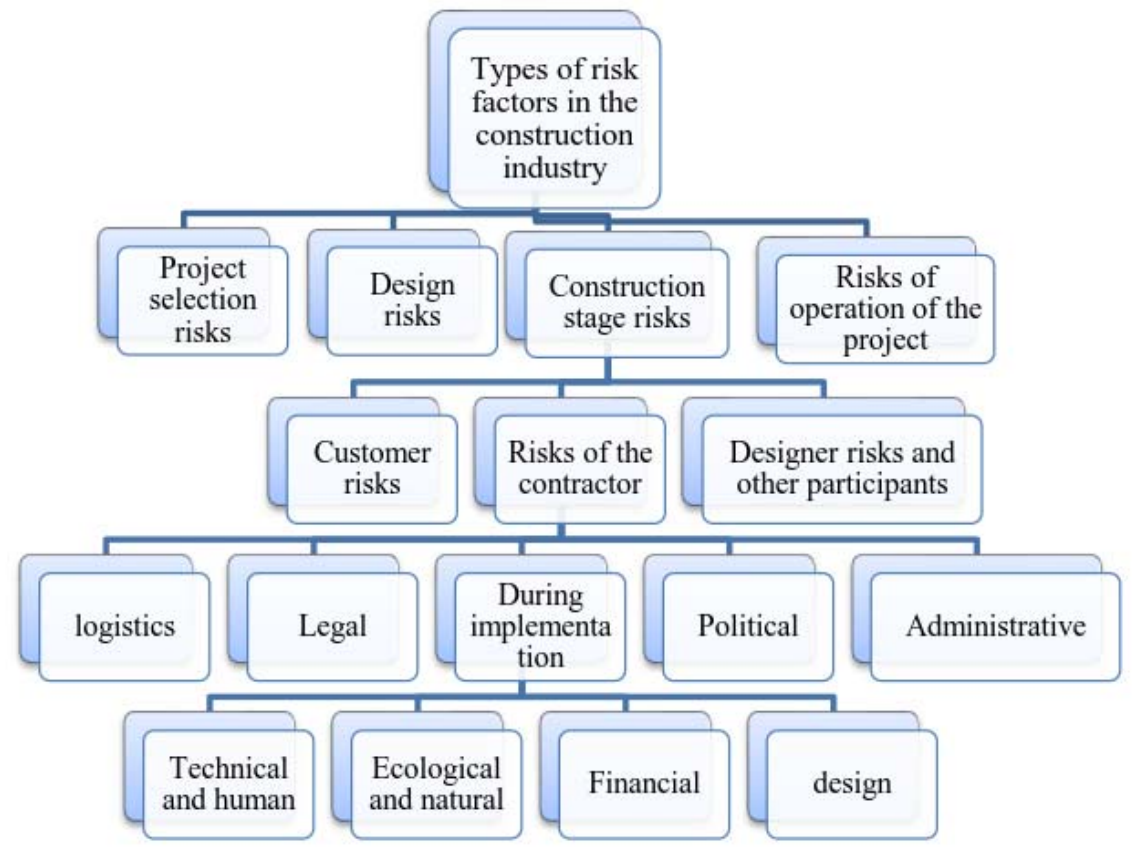

Fig. 1. Types of risk factors in construction projects

\section{Materials and methods}

The questionnaire was prepared and focused on a group of the most common risk factors for investment projects. A questionnaire is an effective way to collect a variety of information from a large number of people with experience. Information was obtained from a number of construction enterprises through direct contact, interviews. For the questionnaire, a Likert scale from 1 to 5 was used.

Risk factors in the questionnaire were divided into several types: technical, organizational, design, executive, legal, managerial, economic, political, environmental, social and safety factors. These risk factors were presented as real and realistic, which are constantly exposed to investment construction projects.

The data were analyzed statistically to determine the degree of importance of risk factors, which were classified by finding the arithmetic mean as shown in table 1 [9-10].

Table 2. Ranking of various risk factors

\begin{tabular}{lll}
\hline Main factors & \multicolumn{1}{c}{ Types of factors } \\
\hline & \multicolumn{1}{l}{1} & Unfinished design \\
\cline { 2 - 3 } Design factors & Inaccurate Determination of the project site \\
\hline 3 & Inconsistency between design parameters and standards \\
\hline 4 & The theoretical scheme does not correspond to reality \\
\hline 5 & Designing changes during implementation \\
\hline 6 & $\begin{array}{l}\text { Non-commitment of engineer with the specified } \\
\text { designs }\end{array}$ \\
\hline 7 & Incorrect assessment of the quantitative \\
\hline 8 & Handing over the project to an inexperienced engineer \\
\hline
\end{tabular}




\begin{tabular}{|c|c|c|}
\hline \multirow{7}{*}{ Organizational Factors } & 9 & $\begin{array}{l}\text { Inconsistency of the order of implementation of } \\
\text { construction work.. }\end{array}$ \\
\hline & 10 & Lack of skilled labor \\
\hline & 11 & Material does not arrive on the site on time \\
\hline & 12 & The variance of workers ' skills in one project \\
\hline & 13 & Low quality of the supplied materials \\
\hline & 14 & $\begin{array}{l}\text { Loss and waste of materials due to negligence of } \\
\text { workers }\end{array}$ \\
\hline & 15 & Theft cases \\
\hline \multirow{4}{*}{ Time factors } & 16 & Slow selection and purchase of materials \\
\hline & 17 & Delayed project due to management problems. \\
\hline & 18 & Unrealistic timeline \\
\hline & 19 & Inability to implement the project on time \\
\hline \multirow{9}{*}{ Technical factors } & 20 & Lack of appropriate mechanisms \\
\hline & 21 & No previous experience with similar projects \\
\hline & 22 & Malfunctions in mechanisms \\
\hline & 23 & New technologies used \\
\hline & 24 & Problems with access to the project site \\
\hline & 25 & Obstacles to use mechanisms on the site \\
\hline & 26 & Inefficiency and inaction of workers \\
\hline & 27 & Labor shortage \\
\hline & 28 & Use of machinery and equipment in an inoperative state \\
\hline \multirow{10}{*}{ Economic forces } & 29 & High wages of workers \\
\hline & 30 & Fluctuating prices for building materials \\
\hline & 31 & high tax rate \\
\hline & 32 & Currency exchange rate changes \\
\hline & 33 & Competition in project pricing \\
\hline & 34 & Delayed payment of subcontractors \\
\hline & 35 & Inflation and price fluctuations \\
\hline & 36 & changes in the Bank's support or creditors \\
\hline & 37 & Inadequate project feasibility study \\
\hline & 38 & Inaccuracy in payment of obligations to executors \\
\hline \multirow{3}{*}{ Safety factors } & 39 & Absence of safety and pollution regulations \\
\hline & 40 & Workplace Injuries and Accidents \\
\hline & 41 & The danger of the materials used \\
\hline \multirow{6}{*}{ Legal factors } & 42 & Incomplete project documentation \\
\hline & 43 & No legal authority to monitor the project \\
\hline & 44 & Problems with accepting payment transactions \\
\hline & 45 & Unclear provisions in the project contract \\
\hline & 46 & Changes in laws and regulations \\
\hline & 47 & Change in the performing enterprise system \\
\hline \multirow{6}{*}{ Management factors } & 48 & Government bureaucracy \\
\hline & 49 & Inappropriate planning and budget \\
\hline & 50 & $\begin{array}{l}\text { Changing the technical characteristics of materials } \\
\text { required during implementation }\end{array}$ \\
\hline & 51 & Change in project management \\
\hline & 52 & Communication problem between project participants \\
\hline & 53 & A large number of competitive construction enterprises \\
\hline \multirow{3}{*}{ Environmental factors } & 54 & Natural disasters (floods, earthquakes, etc.) \\
\hline & 55 & Bad weather condition \\
\hline & 56 & Sudden landslides \\
\hline \multirow{3}{*}{ Social factors } & 57 & Occupational anxiety or stress \\
\hline & 58 & Social events (death, divorce, illness, marital disputes) \\
\hline & 59 & Weak career aspirations of the employee \\
\hline
\end{tabular}


$60 \quad$ Conflicts between workers due to psychological stress

Various risk factors were calculated using statistical methods. The average value indicates the degree of importance or (intensity of influence) of each risk factor. The questionnaire showed a ranking of risk factors included in the construction industry, including economic factors, design, technical, implementation, market, environmental, etc. The following table shows the order of the intensity of the impact of various risk factors [11-12].

Table 3. Rating of the intensity of the influence (Degree of importance) of various risk factors.

\begin{tabular}{cccc}
\hline Number & Types of factors & Degree of importance & Rating \\
\hline 1 & Design factors & 3.144 & 3 \\
\hline 2 & Organizational Factors & 3.221 & 2 \\
\hline 3 & Time factors & 3.019 & 5 \\
\hline 4 & Technical factors & 3.035 & 4 \\
\hline 5 & Economic forces & 3.425 & 1 \\
\hline 6 & Safety factors & 2.855 & 7 \\
\hline 7 & Legal factors & 2.93 & 6 \\
\hline 8 & Management factors & 2.754 & 8 \\
\hline 9 & Environmental factors & 2.705 & 9 \\
\hline 10 & Social factors & 2.024 & 10 \\
\hline
\end{tabular}

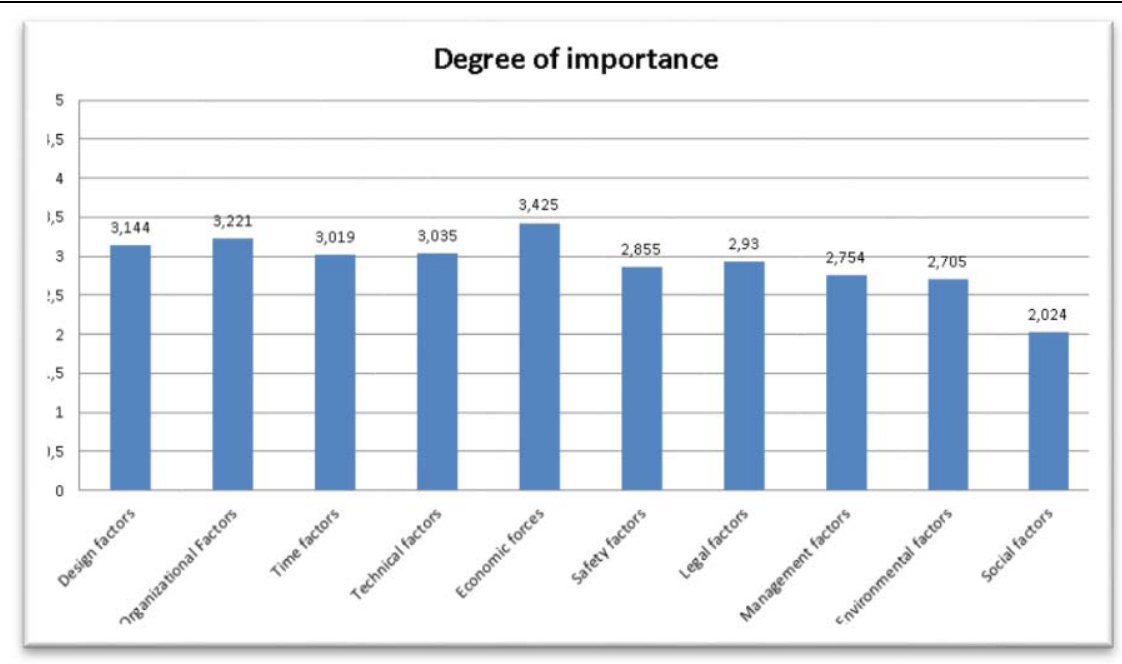

Fig. 2. Ranking chart of various risk factors

Then the degree of importance can be calculated using Monte Carlo simulations as follows, taking data on economic factors, as they gave the highest value in the ranking of the questionnaire.

1. Establishing the probability distribution of important variables:

\begin{tabular}{ccc}
\hline & Frequency & Probability of occurrence \\
\hline 1 & 8 & $8 / 120=0.067$ \\
\hline 2 & 12 & $12 / 120=0.1$ \\
\hline 3 & 42 & $42 / 120=0.35$ \\
\hline 4 & 37 & $37 / 120=0.308$ \\
\hline 5 & 21 & $21 / 120=0.175$ \\
\hline & 120 & $120 / 120=1$ \\
\hline
\end{tabular}

2. Establishing the cumulative probability distribution of variables:

\begin{tabular}{cccccc}
\hline Probability & 0.067 & 0.1 & 0.35 & 0.308 & 0.175 \\
\hline
\end{tabular}




$\begin{array}{llllll}\begin{array}{l}\text { Cumulative } \\ \text { Probability }\end{array} & 0.067 & 0.167 & 0,517 & 0.825 & 1\end{array}$

3. Establishing intervals of random numbers for each variable. This is preparation for using random numbers for modeling:

\begin{tabular}{lccccc}
\hline & 1 & 2 & 3 & 4 & 5 \\
\hline Probability & 0.067 & 0.1 & 0.35 & 0.308 & 0.175 \\
\hline $\begin{array}{l}\text { Cumulative } \\
\text { Probability }\end{array}$ & 0.067 & 0.167 & 0.517 & 0.825 & 1 \\
\hline Intervals, $\%$ & $01-20$ & $21-40$ & $41-60$ & $61-80$ & $81-100$ \\
\hline
\end{tabular}

4. Generation of random numbers (Using Excel)

\begin{tabular}{|c|c|c|c|c|c|c|c|c|c|}
\hline & & & \multicolumn{5}{|c|}{ Table of random numbers } & & \\
\hline 88 & 82 & 60 & 72 & 85 & 53 & 28 & 13 & 59 & 91 \\
\hline 72 & 75 & 58 & 60 & 10 & 71 & 100 & 60 & 80 & 88 \\
\hline 9 & 95 & 32 & 67 & 76 & 89 & 51 & 47 & 88 & 58 \\
\hline 53 & 37 & 22 & 25 & 8 & 24 & 48 & 59 & 54 & 57 \\
\hline 80 & 94 & 23 & 93 & 82 & 53 & 65 & 52 & 94 & 41 \\
\hline 61 & 91 & 53 & 56 & 88 & 18 & 18 & 89 & 25 & 27 \\
\hline 5 & 29 & 81 & 66 & 89 & 78 & 36 & 44 & 38 & 18 \\
\hline 49 & 50 & 13 & 83 & 26 & 97 & 23 & 80 & 40 & 43 \\
\hline 42 & 32 & 32 & 55 & 31 & 83 & 59 & 36 & 41 & 21 \\
\hline 66 & 6 & 4 & 29 & 65 & 79 & 22 & 7 & 8 & 98 \\
\hline
\end{tabular}

5. Modeling multiple experiments for variables means that after choosing a random number for each experiment, the modeling process begins with determining a random number within the intervals performed in step 3 .

\begin{tabular}{lccccccccccc}
\hline $\begin{array}{l}\text { Number } \\
\text { experiments }\end{array}$ & 1 & 2 & 3 & 4 & 5 & 6 & 7 & 8 & 9 & 10 \\
\hline Random numbers & 52 & 37 & 81 & 25 & 98 & 63 & 30 & 49 & 18 & 92 & \\
\hline $\begin{array}{l}\text { simulated number } \\
\text { from 1 to 5 }\end{array}$ & 3 & 2 & 5 & 2 & 5 & 4 & 2 & 3 & 1 & 5 & $\mathbf{3 2}$ \\
\hline
\end{tabular}

Degree of importance for 10 experiments $=\frac{\sum \text { Simulated number }}{\text { Number of experiments }}=\frac{32}{10}=3.2$

Thus, the simulation result was $(3,2)$, not $(3,425)$ as calculated using the statistical method, and if the simulation process is repeated hundreds or thousands of times, the simulation result will be very close to the expected degree of importance, which helps to determine the importance of each risk factor under uncertainty.

\section{Conclusion}

The adoption of a risk assessment framework helps the construction sector accelerate its rate of achievement by developing strategies to cope with potential risks that will support public-private partnerships by building confidence, and the system will encourage banks to accelerate lending and financial closure. It will also lead to focus on contentious points or 
obstacles in the implementation process and achieving quick response, which prevents delays in removing obstacles and using the specified time period to complete the project. Modeling provides insight into the important risk factors to focus on and how their effects overlap.

Therefore, it is necessary to develop methods for quantitative analysis of risk factors (for example, Monte Carlo modeling) that diagnose the main sources and risk factors and their resulting impact on potential costs, integrate risk diagnostics methods for easy and flexible management, and assess their impact on the duration of the project through simulation, which will be explored in future studies.

\section{References}

1. Cooper D.‘Grey S.‘Raymond G.،and Walker P.‘2005- Project Risk Management Guidelines: Managing Risk in Large Projects and Complex Procurements (John Wiley \& Sons‘Ltd, Chichester, 2005)

2. Ivan Abramov, Systemic Integrated and Dynamic Approach As a Basis to Ensure Sustainable Operation of a Construction Company, IOP Conference Series: Materials Science and Engineering 463(3), 032038 (2018)

3. A.M. Privetkina, Risks in the implementation of innovation and investment projects in construction, Issues of Economics and Management 1(8), 22-25 (2017) https://moluch.ru/th/5/archive/51/1714/ (date of access: 09/10/2020).

4. A.A. Lapidus, I.L. Abramov, Sustainability of organizational and production systems in the face of risks and uncertainty in construction production 6, 8-11 (2018)

5. I.L. Abramov, D.S. Saraeva, Research of systemic principles of organization of construction production in conditions of risks and uncertainty, Science and business: ways of development 11 (89), 16-21 (2018)

6. A.A. Sazonov, M.V. Sazonova, Analysis of Risk Factors When Forming an Investment Effectiveness Assessment, Science and Modernity, 158-162 (2016)

7. Fahimeh Allahi, Lucia Cassettari, Marco Mosca, A stochastic risk analysis through monte carlo simulation applied to the construction phase of a $600 \mathrm{mw}$ gas turbine plant, Proceedings of the int. Conference on modeling and applied simulation, 136-143 (2017)

8. Wenzhe Tang 'David M.Young،, Risk Management in the Chinese Construction Industr, Journal of Construction Engineering and Management, (2007)

9. Hashem Al-Hourani, Risk Analysis of Construction Projects in Syria, Al-Baath Magazine 93(8), 55-80 (2017)

10. C.A. Lankina, V.I. Flegontov, Classification and problems of risk assessment of an industrial enterprise 7(3), 1-16 (2015)

11. A.A. Lapidus, I.L. Abramov, Z.A.K. Al-Zaidi, Assessment of the impact of destabilizing factors on implementation of investment and construction projects, IOP Conference Series: Materials Science and Engineering 951, 012028 (2020) doi:10.1088/1757-899X/951/1/012028.

12. A.A. Lapidus, I.L. Abramov, Systemic integrated approach to evaluating the resource potential of a construction company as a bidder, IOP Conference Series: Materials Science and Engineering 603(5), 052079 (2019) 